\title{
PREVALENCE OF OBESITY AND PHYSICAL AND EATING HABITS OF CHILEAN CHILDREN ATTENDING TO SCHOOLS WITH HIGH, MEDIUM AND LOW ACADEMIC ACHIEVEMENT
}

\author{
R. Burrows ${ }^{1}$, C. Ibaceta ${ }^{1}$, Y. Orellana ${ }^{1}$, V. Arancibia ${ }^{2}$, G. Morales $^{3}$, A. Almagliá ${ }^{4}$, P. Lizana ${ }^{4}$, D. Ivanovic ${ }^{1}$ \\ ${ }^{1}$ Institute of Nutrition and Food Thecnology, University of Chile, ${ }^{2}$ Faculty of Social Sciences, School of \\ Psychology, Pontifical Catholic University of Chile, ${ }^{3}$ Faculty of Medicine, University of Chile, Santiago, \\ ${ }^{4}$ Institute of Biology, Laboratory of Physical Anthropology and Human Anatomy, Pontifical Catholic \\ University of Valparaiso, Valparaiso, Chile
}

Background and aims: Familial, socioeconomic and educational factors are important determinants of the prevalence and incidence of obesity in children; low physical activity levels and faulty eating habits in addition to these factors. The aim of this study was to determine in Chilean children, the association between body mass index (BMI), abdominal obesity, physical activity (PAH) and eating (EH) habits with academic achievement of educational institution they attend.

Methods: A representative sample of 26 schools classified with high, medium and low achievement in the SIMCE tests was randomly chosen in the Metropolitan Region of Chile. The sample consisted of 878 schoolage children ( elementary and middle level ) who in 2009 gave the SIMCE (Education Quality System Measurement from the Ministry of Education) tests. BMI, waist perimeter (WP) and physical and eating habits were measured. WHO growth standards, USA reference and habits test "ad hoc" were used we determined BMI z scores, abdominal obesity and quality of habits respectively.

Results: Abdominal obesity prevalence was significantly highest $(\mathrm{p}<0.05)$ in children attending to low and medium ( 39.3\%) than children to high (32.3\%)academic achievement schools. BMI and WC were significantly highest $(\mathrm{p}<0.05)$ in females attending to low and medium than females of high academic achievement schools, without difference in males. Academic achievement showed a directly association ( $\mathrm{p}<$ $0.02)$ with EH and inversely $(\mathrm{p}<0.004)$ association with PAH.

Conclusions: In Chilean children, obesity, Physical and eating habits are associated with academic achievement. 